\title{
Comparison of Monopoly and Sharing Line-haul Vehicles in Express Delivery Service
}

\author{
Friska Natalia Ferdinand \\ Department of Information System, Universitas Multimedia Nusantara, Tangerang, Indonesia \\ Kampus UMN, Scientia Garden, Jl. Boulevard Gading Serpong
}

\begin{abstract}
In the Korean express delivery service market, many companies have been striving to extend their own market share and interested in collaboration through sharing resources such as line-haul vehicles and service centers. Collaboration has recently attracted a great deal of attention as an effective way to secure competitive advantage for companies with limited resources. Some companies operate line-haul vehicles in milk-run types of pick-up and delivery services among consolidation terminals and service centers with locational disadvantages so they can represent as traditional pick-up and delivery problem (PDP). This study proposes the design of express delivery service networks operate only one service center shared by different companies for service centers with low demands by comparing two systems: (i) Monopoly of line-haul vehicles and (ii) Sharing of line-haul vehicles
\end{abstract}

Accepted 13 Mei 2015

Approved 10 Juni 2015
Keywords: Express Delivery Service, Collaborative Network Design, Comparison, Monopoly, Sharing

\section{INTRODUCTION}

The cooperative strategic alliances in the operation of facilities and delivery vehicles may be beneficiary especially for small and medium sized companies to overcome financial problems and improve the profitability by reducing or eliminating overlapped investments. Pick-up and delivery problems (PDPs) are aimed at designing a vehicle route starting and ending at a common depot in order to satisfy pick-up and delivery requests in each location. In a traditional pickup and delivery problem, each customer usually receives a delivery originating from a common depot and sends a pick-up quantity to the same depot. This study proposes a comparison between monopoly collaboration model and sharing collaboration model with make an efficient pickup and delivery system through the strategic alliance of merging under-utilized service centers with low demands. It is suggested that only one company keeps operating a service center for such a location with low demands and other companies in collaboration share it, which will be hereafter called the "monopoly of service centers'. Other companies will use the service center and vehicles at a predetermined price. All the routes should provide pick-up and delivery services, and all the vehicles should return to the depot at the end of each route. The objective of the proposed model is to compare the maximize profit of the two scenarios for each participating company based on the max-min criterion and a genetic algorithm is adapted for solution procedure.

\section{LITERATURE REVIEW}

An express delivery service company needs to provide the vehicles for collecting all requests from the pickup customers and delivering them to the corresponding receiving customers [1]. Many researchers pointed out that different companies owned and operated independently may benefit from the strategic alliance scheme which is conceptually similar to facility sharing and a methodology for optimizing capacity allocation was proposed in previous study [2]. The case study related to the express courier service network design considering strategic alliance was proposed in [3], which proposed a network design model for strategic alliances among express 
courier service companies by the monopoly of service centers and they extended their previous study to the problem of sharing consolidation terminals of participating companies by using strategic alliance [4] and using fuzzy set approach [5]. A nonlinear integer programming model for a strategic alliance among express companies is proposed and a fuzzy set theoretic solution procedure is used in [6] by considering the survival of multiple service centers in merging regions. An optimization model for a profitable tour design with pickup and delivery based on a multi-objective formulation involving single and multiple companies allied for resource sharing was developed in [7] and [8]. After these two studies, [1] extended the study of a network design for the profitable tour problem with pickup and delivery visits. The main idea of this study is investigated in [9] operate only one service center shared by different companies for service centers with low demands and change the visit schedules accordingly and [10] using strategic partnership among express delivery service companies by creating the monopoly of service centers in PDP of line-haul vehicles and separate pickup and delivery routing for profit maximization. The objective of this study is to compare the maximize the profit of the two scenarios for each participating company based on the max-min criterion with the assumption (i) The delivery and pickup processes may not be performed by the different vehicle(monopoly line-haul vehicle) and (ii) can be performed by the different vehicle (sharing line-haul vehicles). This study considers the design of express delivery service networks considering two main factors: First, only one company keeps operating service centers for locations with low demands and others share it at a predetermined cost. Second, each company operates their line-haul vehicles by considering two scenarios for pickup and delivery and thus the visit schedules and routing in PDP are set up separately.

\section{PROBLEM STATEMENT}

This study provides two scenarios which compare the profitable tour problem considering collaboration among several companies providing pick-up and delivery services along the same route. The main idea of this study is that only one company will operate a service center for a location and share it with other collaborating companies. Each company operates their linehaul vehicles by comparing: (i) monopoly and (ii) sharing their pick-up and delivery routes are determined with the consideration of monopoly of service center.

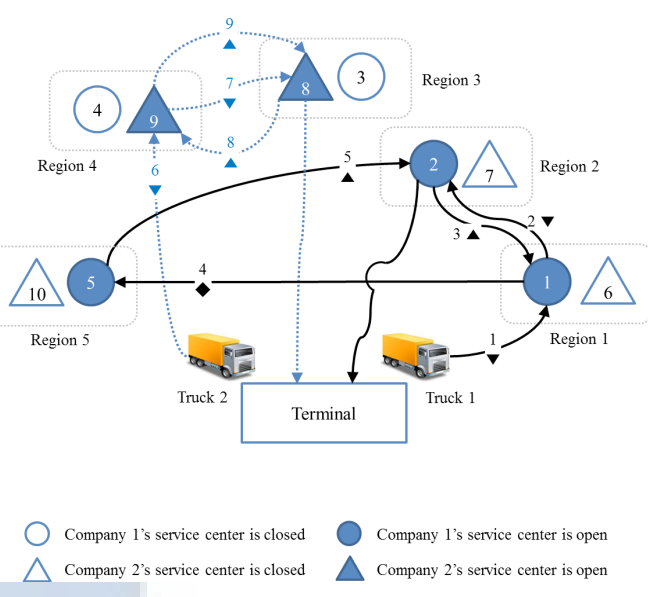

Figure 1. Tour sequence in the PDPs process after applying the alliance model with monopoly of line-haul vehicles

The first scenario is developed based on the following assumptions:

(i) For each location, only one company will operate a service center and the other companies will share it at a predetermined price;

(ii) The amount of pick-up and delivery requests of all companies at each location will be automatically moved to the monopolized service center; and

(iii) Delivery and pick-up requests can be processed only by same vehicles.

The second scenario is developed based on the following assumptions:

(i) For each location, only one company will operate a service center and the other companies will share it at a predetermined price;

(ii) The amount of pick-up and delivery 
requests of all companies at each location will be automatically moved to the monopolized service center; and

(iii) Sharing vehicles is considered for delivery and pick-up requests.

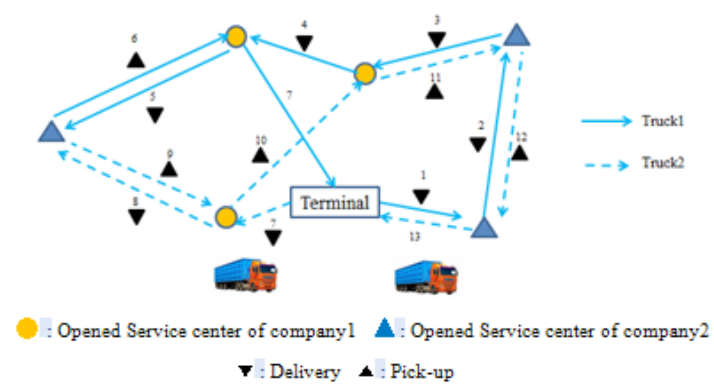

Figure 2. Tour sequence in the PDPs process after applying the alliance model with sharing of line-haul vehicles

\section{SOLUTION PROCEDURE AND RESULTS}

In this study considered there are two express delivery service companies with one consolidation terminal and five locations which are identical for two companies. It is also assumed that each company has one vehicle and in the first scenario: they cannot share the vehicles for pick-up and delivery while in the second scenario they may share the vehicles for pick-up and delivery.

Genetic Algorithm (GA) is applied in this study and the proposed algorithm is to convert PDP to TSPs. Suppose that there are $n$ service centers with pick-up and delivery, one may generate $n$ service centers with delivery only and $n$ service centers with pick-up only. Considering the linked consolidation terminal, PDP with $\mathrm{n}$ service centers may be converted to a TSP and after a PDP is converted to a TSP then GA is applied to solve this problem. GA is generally referred to as a stochastic solution search procedure that is proven to be useful for solving combinatorial problems using the concept of evolutionary computation imitating the natural selection and biological reproduction of animal species $[11,12]$.
The GA parameters used in this study are as follows: Cloning rate: $2 \%$, Crossover rate: 50 - 70\%, Mutation rate: 4 - 6\%, Population size: 100 and Maximum number of generations: 100 . These are the methods of GA that used in this study: roulette wheel selection, partial mapped crossover, and swap mutation.

The development of GA algorithm is explained in the following: (i) First Scenario and (ii) Second scenario. The first scenario's chromosome representation and steps of crossover can be seen in Figure 3. There are 15 genes in this chromosome expressed by binary and string values. The first 5 genes represent the status of each company's service center in each region by using binary values ( 0 : company 1 's service center is open, 1 : company 2's service center is open).

\begin{tabular}{|c|c|c|c|c|c|c|c|c|c|c|c|c|c|c|}
\hline \multicolumn{5}{|c|}{ Service Center } & \multicolumn{4}{|c|}{ Truck 1} & \multicolumn{6}{|c|}{ Truck 2} \\
\hline R1 & R2. & R3 & $\mathrm{R} 4$ & R5 & 1 & 2 & 3 & 4 & 5 & 6 & 7 & 8 & 9 & 10 \\
\hline 1 & 0 & 1 & 1 & 0 & 'D2' & 'D5 & 'P2' & 'P5 & 'D6 & 'Dg & 'D8' & 'PS & 'P9' & 'P6 \\
\hline & 5 Gen & & & & & & & & & & & & & \\
\hline
\end{tabular}

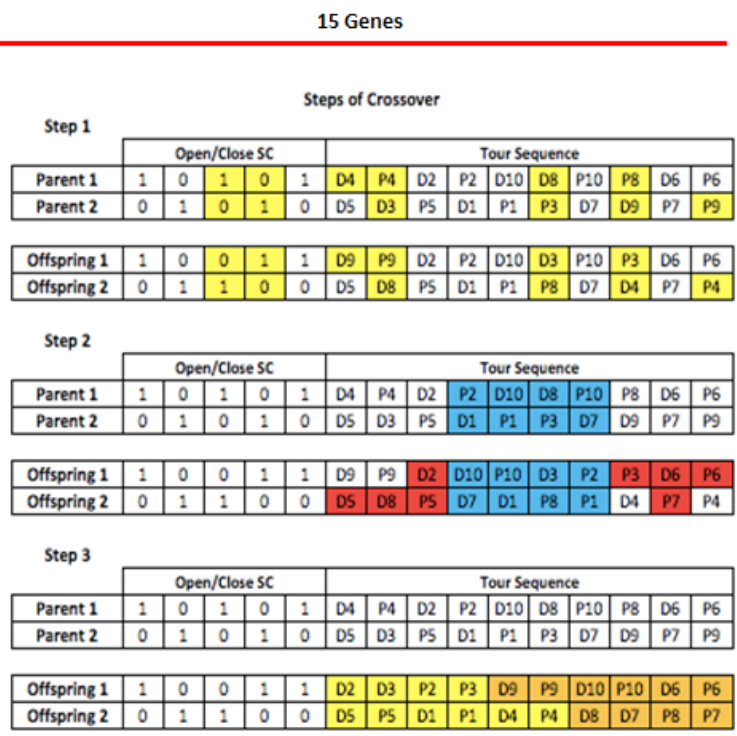

Figure 3. The first scenario's chromosome representation and steps of crossover

In Figure 4 represents the chromosome representation of second scenario and the step of crossover. In this scenario there are 17 genes in this chromosome expressed by binary and string 
values. The first 5 genes represent the status of each company's service center in each region by using binary values ( 0 : company 1 's service center is open, 1: company 2's service center is open). The sixth and seventh genes are the number of service centers that will be handled by each truck (00: one truck handles 3 centers and the other handles 7 centers, 01: 4 and 6,10: 5 and 5, 11: choose one among cases 0,1 , and 2 ). The remains genes explain the tour sequence which represented by string values and also considers the vehicle sharing between two companies. The nodes 1 through 5 are for company 1's service centers and the remainder corresponds to company 2's service centers. It should be noted that both companies have their own service center at each location but they operate the service centers according to the value of first five genes. The partial mapped crossover is used in the crossover process, which passes ordering and value information from the parent tours to the offspring which the chromosome cannot contain duplicate values. The process interchange of binary string values: mapped from a portion of one parent string onto a portion of the other parent string while the remaining string values are exchanged and the last process is validation of Pick-up and Delivery Sequence.

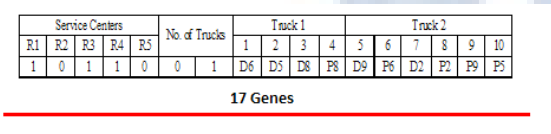

Opening or Closing Service Centers in Each Region \begin{tabular}{|c|c|c|c|c|}
\hline \multicolumn{3}{|c|}{ Service Centers } \\
\hline R1 & R2 & R3 & R4 & R5 \\
\hline 1 & 0 & 1 & 1 & 0 \\
\hline
\end{tabular}

Truck assignments \begin{tabular}{|c|c|c|c|c|c|c|c|c|c|c|c|}
\hline \multicolumn{2}{c|}{$\begin{array}{c}\text { No. of } \\
\text { Trucks }\end{array}$} & \multicolumn{3}{|c|}{ Truck 1 } & \multicolumn{5}{c|}{ Truck 2 } \\
\cline { 2 - 9 } & 1 & 2 & 3 & 4 & 5 & 6 & 7 & 8 & 9 & 10 \\
\hline 0 & 1 & D6 & D5 & D & P8 & D9 & P6 & D2 & P2 & P9 & P5 \\
\hline
\end{tabular}

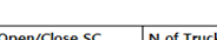

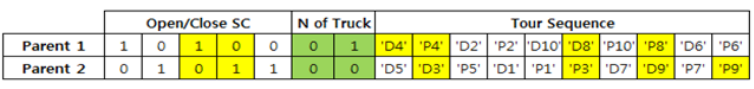

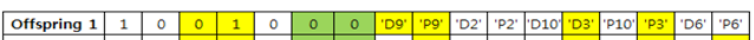

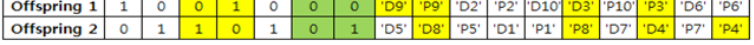

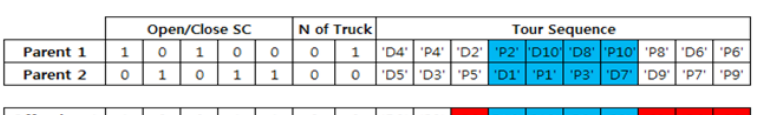

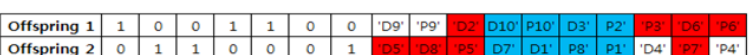

Figure 4. The second scenario's chromosome representation and steps of crossover
The swap mutation is adopted as a mutation operator in the first and second scenarios. There are two parts in the mutation process: the first part swaps the genes in binary values (first genes and fourth genes are interchanged) and the second part swaps the genes represented in string values (second genes and third genes are interchanged).

Table 1 shows the current operation data of each service center and Table 2 shows the travel distance matrices between terminal and each service center (Company 1: nodes 1-5, Company 2: nodes 6-10). It is also assumed that 5 minutes are required for preparing the package loading/ unloading tasks in the service center, and 0.03 minutes of package handling is required for each package. The upper bound of trip time is 12 hours, and the capacity for each vehicle is 3000 units.

Table 1. The first and second scenario's daily amounts of delivery and pick-up for each service center

\begin{tabular}{|c|c|c|c|c|c|c|}
\hline \multirow{2}{*}{ Company } & \multirow[b]{2}{*}{ Regions } & \multicolumn{4}{|c|}{ Daily Amounts } & \multirow{2}{*}{$\begin{array}{l}\text { Daily } \\
\text { Fixed } \\
\text { Cost }\end{array}$} \\
\hline & & Delivery & $\begin{array}{l}\text { Pick- } \\
\text { up }\end{array}$ & $\mathrm{a}_{\mathbf{j}}$ & $\mathrm{b}_{j}$ & \\
\hline \multirow{5}{*}{1} & 1 & 160 & 200 & 0.2 & 0.02 & 52 \\
\hline & 2 & 20 & 40 & 0.1 & 0.01 & 88 \\
\hline & 3 & 120 & 100 & 0.2 & 0.02 & 64 \\
\hline & 4 & 20 & 20 & 0.1 & 0.01 & 78 \\
\hline & 5 & 60 & 80 & 0.1 & 0.01 & 75 \\
\hline \multirow{5}{*}{2} & 1 & 40 & 20 & 0.1 & 0.01 & 71 \\
\hline & 2 & 400 & 500 & 0.3 & 0.03 & 57 \\
\hline & 3 & 150 & 180 & 0.2 & 0.02 & 91 \\
\hline & 4 & 20 & 40 & 0.1 & 0.01 & 83 \\
\hline & 5 & 100 & 180 & 0.2 & 0.02 & 61 \\
\hline
\end{tabular}

Table 2. The first and second scenario's travel times among consolidation terminal and service centers

\begin{tabular}{|l|l|l|l|l|l|l|l|l|l|l|}
\hline \multicolumn{1}{|c}{$\mathbf{1}$} & $\mathbf{2}$ & $\mathbf{3}$ & $\mathbf{4}$ & $\mathbf{5}$ & $\mathbf{6}$ & $\mathbf{7}$ & $\mathbf{8}$ & $\mathbf{9}$ & $\mathbf{1 0}$ \\
\hline $\mathbf{T}$ & 38 & 72 & 18 & 11 & 17 & 39 & 50 & 23 & 56 & 42 \\
\hline $\mathbf{1}$ & 0 & 25 & 32 & 43 & 13 & 41 & 30 & 42 & 74 & 27 \\
\hline $\mathbf{2}$ & 0 & 0 & 24 & 55 & 23 & 34 & 71 & 29 & 38 & 19 \\
\hline $\mathbf{3}$ & 0 & 0 & 0 & 16 & 69 & 26 & 42 & 41 & 35 & 67 \\
\hline $\mathbf{4}$ & 0 & 0 & 0 & 0 & 41 & 18 & 15 & 23 & 31 & 13 \\
\hline $\mathbf{5}$ & 0 & 0 & 0 & 0 & 0 & 19 & 45 & 20 & 33 & 54 \\
\hline $\mathbf{6}$ & 0 & 0 & 0 & 0 & 0 & 0 & 17 & 52 & 48 & 16 \\
\hline $\mathbf{7}$ & 0 & 0 & 0 & 0 & 0 & 0 & 0 & 13 & 49 & 21 \\
\hline $\mathbf{8}$ & 0 & 0 & 0 & 0 & 0 & 0 & 0 & 0 & 32 & 43 \\
\hline $\mathbf{9}$ & 0 & 0 & 0 & 0 & 0 & 0 & 0 & 0 & 0 & 22 \\
\hline $\mathbf{1 0}$ & 0 & 0 & 0 & 0 & 0 & 0 & 0 & 0 & 0 & 0 \\
\hline
\end{tabular}


Table 3 shows the comparison result after a GA-based heuristic is applied to the example problem based on the max-min criterion. It is obtained that the incremental profits and travel times for each scenario: 2:45:56 hours for truck 1and 2:26:11 for truck 2, with the profits are: $\$ 232$ for company 1 and $\$ 232$ for company 2; 1:30:49hours for truck 1and 1:46:13 for truck 2 , with the profits are: $\$ 264$ for company 1 and \$294 for company 2 respectively. We observe that although the travel time for each vehicle is longer, more incremental profits of $\$ 34.1$ are realized. The result is to reconfigure the route so that the profit is maximized. Each service center has two different nodes, one for delivery, and the other to pick-up. Thus, there are ten nodes for five service centers. Therefore, the problem can be viewed as a TSP departing from and returning to the consolidation terminal with ten nodes visiting in the meantime, of which objective function is to maximize the total revenue. Figure 5 shows the first scenario's tour sequence The tour sequence is T-R4C1D-R1C1D-R5C1SR1C1P-T and T-R3C2D-R2C2D-R3C2P R2C2P $-T$ for each vehicle respectively. Figure 6 shows the second scenario's tour sequence with the tour sequence for truck 1: T-R4C1D-R3C2S-R5C1ST and truck 2: T-R4C1P-R2C2S-R1C2S- T after GA implementation.

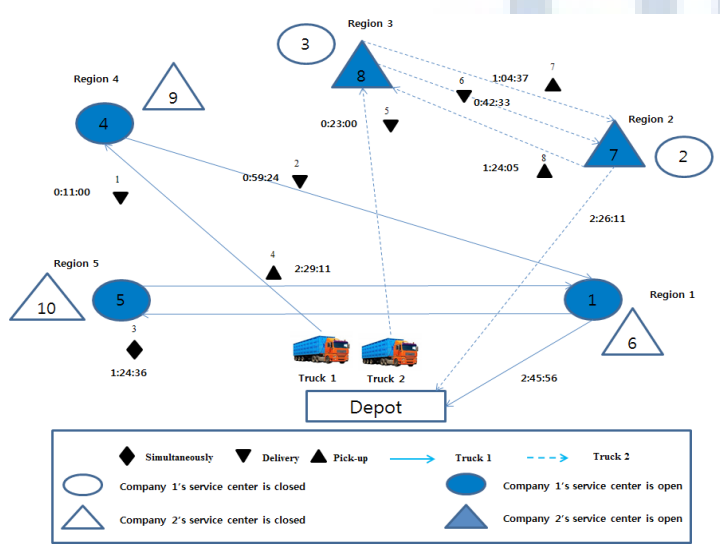

Figure 5. The first scenario's result

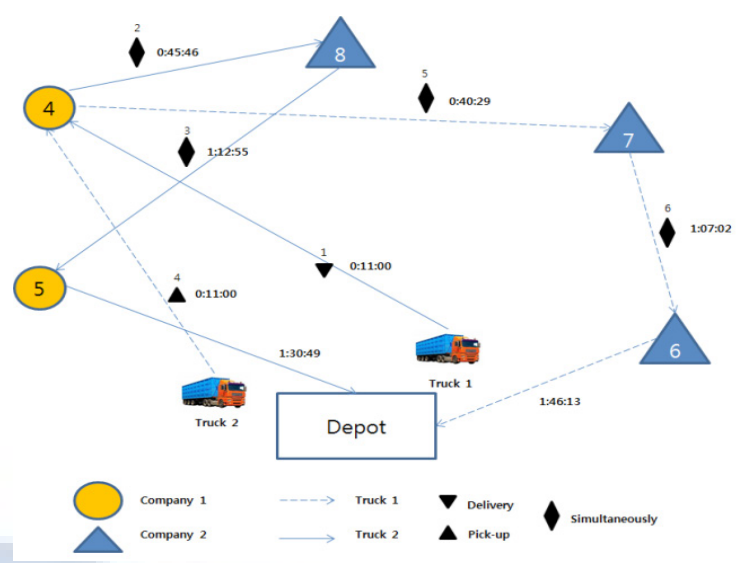

Figure 6 . The second scenario's result

Table 3. The comparison result after GA implementation

\begin{tabular}{|c|c|c|}
\hline & Scenario 1 & Scenario 2 \\
\hline Truck 1 & $2: 45: 56$ & $1: 30: 49$ \\
\hline Truck 2 & $2: 26: 11$ & $1: 46: 13$ \\
\hline $\begin{array}{c}\text { First Part } \\
\text { Revenue }\end{array}$ & $\$ 232 \& \$ 232$ & $\$ 264 \& \$ 294$ \\
\hline $\begin{array}{c}\text { Second Part } \\
\text { Revenue }\end{array}$ & $\$ 20.40$ & $\$ 54.50$ \\
\hline
\end{tabular}

\section{CONCLUSIONS}

The problem of express delivery service network is investigated with the consideration of strategic alliance among companies based on a max-min criterion by comparing two scenarios: (i) Monopoly line-haul vehicles and (ii) sharing service line-haul vehicles. This study proposes that companies may collaborate by sharing line-haul vehicles especially when there are not enough demands for pick-up and delivery which can increase their profit compared to monopoly line-haul vehicle.

It is also discussed that the PTP with pick-up and delivery may be converted to Travel Salesman Problem and the problem is formulated on the basis of max-min decision criterion to resolve the conflicting interests among participating companies. A heuristic solution procedure based on GA is developed and demonstrated through an illustrative example. Opportunities for future 
research may consist in the consideration of various types of collaborations to extend the proposed procedure.

\section{REFERENCES}

[1] F.N. Ferdinand., I.K. Moon, and C.S. Ko., "A Pick-up and Delivery Service Network Design Model among Service Centers with Low Demands in Express Delivery Services", ICIC Express Letters: International Journal of Research and Surveys, vol 7(6), pp: 1819-1825, 2013.

[2] F.N. Ferdinand. and C.S. Ko., "A genetic algorithm-based heuristic for network design of service centers with pick-up and delivery visits of mandated vehicles in express delivery service industry", Journal of the Korean Society of Supply Chain Management, vol 14, pp :77-83, 2014

[3] W. Cheung, L.C. Leung, and Y.M.Wong, "Strategic service network design for DHL Hong Kong. Interfaces", vol. 31, pp: 1-14, 2001.

[4] Chung, K.H., Rho, J.J., and Ko, C.S., "Strategic alliance model with regional monopoly of service centers in express courier services", International Journal of Service and Operation Management, vol. 5, no.6, pp.774-786, 2009.

[5] Chung, K.H., Ko, C.S., Hwang, Y.M., and Rho, J.J., "Network design for strategics alliance in express courier services: a fuzzy set approach, International Journal of Innovative Computing", Information and Control, vol. 9, no.1, pp.349359,2010 .

[6] Chung, K.H., Ko, H.J., Ferdinand, F.N., and Ko, C.S., "A Fuzzy Set-Theoretic Approach to the Weak Strategic Alliance for the Survival of Multiple Service Centers in Express Courier Services", ICIC Express Letters: International Journal of Research and Surveys, vol.5, no.2, pp.385-389, 2011.
[7] Y.J. Kim, F.N. Ferdinand, H.K. Lee, C.S. Ko, "Collaboration-Based Profitable Tour Design with Pick-up and Delivery in Express Courier Services", ICIC Express Letters: International Journal of Research and Surveys, 5, 10, 36253630, 2011.

[8] Y.J. Kim, F.N. Ferdinand, H.K. Lee, C.S. Ko, "Multi-objective Profitable Tour Design with Strategic Alliance Scheme in Express Courier Services", ICIC Express Letters: International Journal of Research and Surveys, 6, 4, 923-928, 2012.

[9] F.N. Ferdinand, Y.J. Kim, E.G. Lee, C.S. Ko (2013), "Strategic partnership based network design in express delivery services: monopoly of service centers and separate pick-up and delivery routing”, Proc. of APIEMS 2013, Phillipines.

[10] F.N. Ferdinand, Y.J. Kim, H.K. Lee, C.S. Ko , "A study on collaborative pick-up and delivery routing problem of line-haul vehicles in express delivery services", International Journal of Industrial Engineering: Theory, Applications and Practice, 21(1), 99-111, 2014

[11] M. Gen and R.Cheng, Genetic Algorithms andEngineering Optimization,New York: Wiley, 2000

[12] Goldberg, D. E. (1989), Genetic Algorithms in Search,Optimization and Machine Learning, Reading, MA: Addison Wesley 